\title{
A randomised crossover study investigating the effects of galacto-oligosaccharides on the faecal microbiota in men and women over 50 years of age
}

\author{
Gemma E. Walton ${ }^{1 *}$, Ellen G. H. M. van den Heuvel$^{2}$, Marit H. W. Kosters ${ }^{2}$, Robert A. Rastall ${ }^{1}$, \\ Kieran M. Tuohy ${ }^{1}$ and Glenn R. Gibson ${ }^{1}$ \\ ${ }^{1}$ Department of Food and Nutritional Sciences, The University of Reading, Reading RG6 6AP, UK \\ ${ }^{2}$ FrieslandCampina-Research, Deventer, The Netherlands
}

(Submitted 21 February 2011 - Final revision received 24 June 2011 - Accepted 21 July 2011 - First published online 13 September 2011)

\begin{abstract}
Faecal microbial changes associated with ageing include reduced bifidobacteria numbers. These changes coincide with an increased risk of disease development. Prebiotics have been observed to increase bifidobacteria numbers within humans. The present study aimed to determine if prebiotic galacto-oligosaccharides (GOS) could benefit a population of men and women of 50 years and above, through modulation of faecal microbiota, fermentation characteristics and faecal water genotoxicity. A total of thirty-seven volunteers completed this randomised, double-blind, placebo-controlled crossover trial. The treatments - juice containing $4 \mathrm{~g}$ GOS and placebo - were consumed twice daily for 3 weeks, preceded by 3 -week washout periods. To study the effect of GOS on different large bowel regions, three-stage continuous culture systems were conducted in parallel using faecal inocula from three volunteers. Faecal samples were microbially enumerated by quantitative PCR. In vivo, following GOS intervention, bifidobacteria were significantly more compared to post-placebo $(P=0 \cdot 02)$. Accordingly, GOS supplementation had a bifidogenic effect in all in vitro system vessels. Furthermore, in vessel 1 (similar to the proximal colon), GOS fermentation led to more lactobacilli and increased butyrate. No changes in faecal water genotoxicity were observed. To conclude, GOS supplementation significantly increased bifidobacteria numbers in vivo and in vitro. Increased butyrate production and elevated bifidobacteria numbers may constitute beneficial modulation of the gut microbiota in a maturing population.
\end{abstract}

\section{Key words: Prebiotics: Bifidobacteria: Galacto-oligosaccharides: Intestine: Microbiotica: Age: Faecal water}

The colonic microbiota ferment endogenous and undigested dietary sources of carbohydrates and proteins. In the proximal regions (caecum and ascending colon) carbohydrates are readily digested, more distally carbohydrates are in short supply and protein fermentation predominates ${ }^{(1,2)}$. Protein fermentation is associated with negative end products such as ammonia, amines, phenols and indoles ${ }^{(2)}$. Such compounds are undesirable due to their potentially toxic nature ${ }^{(3)}$. Ammonia, for example, has cytopathic cellular effects ${ }^{(4)}$, through increasing cellular turnover and increasing vulnerability to DNA damage ${ }^{(5)}$.

Studies of the microbiota of populations over 60 years of age have frequently indicated an altered bacterial composition towards that of a more proteolytic one ${ }^{(6,7)}$. The faecal flora changes have been observed to differ between populations within different countries ${ }^{(8)}$. Lower levels of Clostridium cluster XIVa and Faecalibacterium prausnitzii, which are known butyrate producers, have been observed in older volunteers $^{(8,9)}$. The use of traditional culturing has indicated reduced bifidobacteria numbers and diversity in ageing groups ${ }^{(10,11)}$. In more recent studies, with the use of molecular characterisation techniques, Zwielehner et ll $^{(12)}$ showed reduced bifidobacterial diversity in a cohort of people aged 78-94 years. A study on an Italian population of adults, elderly and centenarians found only the centenarians to have significantly lower bifidobacteria ${ }^{(13)}$; however, Italian populations have previously been observed to have higher levels of bifidobacteria than other populations ${ }^{(8)}$. A study by Rajilić-Stajonović did not observe differences in bifidobacteria numbers in the microbiota of young adults and the elderly ${ }^{(9)}$; however, the younger group was from five different European countries $^{(14)}$, which is likely to make an impact on the microbiota $^{(8)}$. Furthermore, different DNA extraction techniques were used for the two groups. Mäkivuokko observed low levels of bifidobacteria in all volunteers when characterising the microbiota of young adults and the elderly. The authors

Abbreviations: CFU, colony-forming units; GOS, galacto-oligosaccharides.

* Corresponding author: G. E. Walton, fax +44 118931 0080, email g.e.walton@reading.ac.uk 
attributed these low levels to a mismatch in the bifidobacteria primers used $^{(7)}$. The elderly microbiota does appear to show temporal stability ${ }^{(15)}$; however, the Actinobacteria group, which encompasses Bifidobacterium spp., has been observed to be temporally unstable ${ }^{(9)}$. Therefore, microbiota in the elderly and young adults have been observed to show alterations that coincide with dietary changes including increased protein intake ${ }^{(16)}$ and activity changes such as reduced exercise levels ${ }^{(17,18)}$. These microbial and fermentation changes and instability may have a role to play in some of the health changes that occur while ageing, as they reportedly often coincide with increased susceptibility to gastroenterological infection $^{(19)}$, immune function and chronic diseases such as colon cancer ${ }^{(16)}$.

A prebiotic is 'a selectively fermented ingredient that results in specific changes, in the composition and/or activity of the gastrointestinal microbiota, thus conferring benefit(s) upon host health ${ }^{, 20)}$. Galacto-oligosaccharides (GOS) are prebiotics that have been shown in human feeding studies to selectively stimulate the growth of bifidobacteria ${ }^{(21-24)}$ and lactobacilli $^{(25,26)}$. Indeed, human studies on infants have shown GOS to offer benefits in terms of stool consistency, while increasing bifidobacterial numbers ${ }^{(27)}$; in adults, GOS have also been seen to alleviate symptoms of irritable bowel syndrome ${ }^{(21)}$.

The aim of the present study was to evaluate whether GOS lead to a beneficial shift in the faecal microbiota in a population of men and women over 50 years of age, while beneficially affecting fermentation characteristics. This was assessed in vitro and in vivo.

\section{Experimental methods}

A total of thirty-nine volunteers aged 50-81 years (58.9 (SD 5.9) years), with a BMI of $19.7-38.4 \mathrm{~kg} / \mathrm{m}^{2}\left(26.05(\mathrm{SD} 3.63) \mathrm{kg} / \mathrm{m}^{2}\right)$, were recruited for the study. None of their first-degree relatives had bowel cancer while under 50 years of age. Volunteers were excluded on the grounds of receiving antibiotic therapy or medication active on the gastrointestinal tract within 3 months of the start of the study. Volunteers were asked not to consume prebiotic supplemented foods and to refrain from consumption of probiotics, such as yoghurts, before and during the study and for the run-in period of 4 weeks before the start of the study. This study was conducted according to the guidelines laid down in the Declaration of Helsinki and all procedures involving human subjects were approved by the University of Reading Research and Ethics Committee. Written informed consent was obtained from all subjects. Of the volunteers, twenty-one were female and the remaining eighteen were male, of which three were current smokers. Two of the volunteers (both male) consumed antibiotics during the second treatment of the study; therefore, their results have not been included in the mean data or statistical analyses.

The prebiotic used was GOS (Vivinal GOS; Friesland Campina Domo, Zwolle, The Netherlands). Volunteers were given this prebiotic within an orange juice preparation at a concentration of $4 \mathrm{~g}$ GOS per serving (comparable to $9 \mathrm{~g}$ Vivinal GOS syrup: 59\% GOS, 21\% lactose, 19\% glucose,
$1 \%$ galactose on DM with degrees of polymerisation ranging between 2 and 8). The unsupplemented placebo orange juice product had an identical taste and mouthfeel; however, it contained approximately $4 \mathrm{~g}$ less simple sugars than the Vivinal GOS juice preparation. The juices were consumed twice daily by the volunteers, preferably in the morning and evening $(2 \times 250 \mathrm{ml} / \mathrm{d})$.

The present study was a double-blind, placebo-controlled crossover feeding trial. Volunteers were randomly assigned into two groups; one starting with the placebo juice preparation, the other with the GOS-containing juice. Volunteers consumed the products for 3 weeks, followed by a 3-week washout period (no treatment products consumed); the remaining treatment was consumed over the next 3 weeks, preceded by a final 3-week washout period. Volunteers were required to visit the University of Reading (Reading, UK) on six occasions in total and to provide a faecal sample at each visit (1 week before the start; on day 0; and after 3, 6, 9 and 12 weeks).

\section{Volunteer diaries}

Volunteers were asked to maintain a normal diet throughout the study and to complete detailed food diaries during any 3 consecutive study days. These diaries were analysed using Foodbase 3.1 (Institute of Brain Chemistry and Human Nutrition, University of North London, London, UK). Daily diaries with general questions concerning bowel habit and mood were also given to volunteers to complete.

\section{Collection of faecal samples}

Volunteers were provided with plastic containers in which to provide a fresh faecal sample on site at the Department of Food and Nutritional Sciences. Samples were placed into an anaerobic cabinet $\left(\mathrm{H}_{2}: \mathrm{CO}_{2}: \mathrm{N}_{2}, 10: 10: 80\right.$ by volume at $\left.37^{\circ} \mathrm{C}\right)$ and processed within $30 \mathrm{~min}$ of voiding. In the event that a volunteer was unable to provide a sample, a further day's supplement was issued and the volunteer returned a day later.

\section{Faecal water isolation}

A $50 \%(\mathrm{w} / \mathrm{v})$ faecal slurry in ice-cold PBS $(0 \cdot 1 \mathrm{~mol} / \mathrm{l}, \mathrm{pH} 7)$ was homogenised for $3 \mathrm{~min}$. The slurry was immediately frozen at $-70^{\circ} \mathrm{C}$ where it was stored for up to 2 weeks. The sample was ultra-centrifuged at $65000 \mathrm{~g}$ for $2 \mathrm{~h}$ at $4^{\circ} \mathrm{C}$. The remaining supernatant was filtered initially through a $0.2 \mu \mathrm{m}$ PVDF filter (Whatman, Kent, UK). Samples were stored at $-70^{\circ} \mathrm{C}$ until commencement of the comet assay.

\section{Bacteriology}

A $10 \%(\mathrm{w} / \mathrm{v})$ faecal slurry in anaerobic PBS (0.1 mol/1, pH 7) was made for assessment of bacteriology. The slurry was homogenised for $2 \mathrm{~min}$. Faecal slurry $(1 \mathrm{ml})$ was centrifuged for $5 \mathrm{~min}$ at $13400 \mathrm{~g}$. The pellet was frozen and used for DNA extraction, for quantitative PCR analysis. For fluorescence in situ hybridisation, the samples were processed 
and the analysis was conducted according to the method used by Probert et al. ${ }^{(28)}$, using the probes (Erec482, target group Eubacterium rectale-Clostridium coccoides $52^{\circ} \mathrm{C}: 5^{\prime}$ GCTTCTTAGTCAGGTACCG- $3^{\prime(29)}$ ) and CHIS150, target group Clostridium perfringens-histolyticum subgroup $50^{\circ} \mathrm{C}$ : $5^{\prime}$ TTATGCGGTATTAATCT(T/C)CCTTT $3^{\prime(29)}$ ).

\section{Bacterial DNA extraction}

Bacterial DNA was isolated from the frozen pellet using a Qiagen (West Sussex, UK) stool kit according to the manufacturer's instructions. Initially, the pellet was incubated at $37^{\circ} \mathrm{C}$ for $40 \mathrm{~min}$ in enzyme solution ( $3 \mathrm{mg}$ lysozyme, 100 units mutanolysin in $100 \mu \mathrm{l}$ Tris-EDTA buffer (10 mm-Tris, $1 \mathrm{mm-EDTA})$ ) to aid breakdown of the cell walls. Then, the solution was mixed with $1.4 \mathrm{ml}$ stool lysis buffer and the Qiagen protocol followed.

\section{Quantitative PCR}

The quantitative PCR was conducted from an adapted method of Ritalahti et al. ${ }^{(30)}$. Briefly, $5 \mu \mathrm{l}$ of DNA samples/standards were applied to each well. To this, $20 \mu \mathrm{l}$ mastermix solution (Applied Biosystems, Foster City, CA, USA) including relevant primer sets and probes with 6-carboxyfluorescein (6-FAM) as a reporter fluorophore on the $5^{\prime}$ end, with dihydrocyclopyrroloindole tripeptide minor groove binder quencher on the $3^{\prime}$ end (Table 1). For total bacteria, SYBR Green mix was used $^{(30)}$. The plate was covered with an optical adhesive cover (Applied Biosystems) and placed into the AB 7700 sequence detector (Applied Biosystems), which was used in conjunction with Sequence Detector System software (Applied Biosystems). Temperatures used for starting, denaturing, annealing and final temperatures were $50^{\circ} \mathrm{C}, 95^{\circ} \mathrm{C}, 60^{\circ} \mathrm{C}$ and $50^{\circ} \mathrm{C}$, respectively. However, total bacteria had an annealing temperature of $58^{\circ} \mathrm{C}$ and lactobacilli an annealing temperature of $64^{\circ} \mathrm{C}$. The denaturing and annealing sequence was repeated forty times. Primers used in the present study were designed by Nauta et al. ${ }^{(31,32)}$, based on the $16 \mathrm{~s}$ ribosomal RNA sequences derived from the ribosomal project database.

\section{Faecal water genotoxicity}

The single-cell gel electrophoresis assay was conducted on the baseline faecal water sample for all volunteers. The five volunteers whose baseline samples caused the most DNA damage to the HT29 cells were investigated for the remaining time points. Briefly, HT29 cells were harvested at a concentration of $2.5 \times 10^{7}$ cells $/ 1$. From this, $350 \mu \mathrm{l}$ of cell suspension were mixed with $150 \mu$ l faecal water (i.e. $30 \%$ as determined by calibration) or with controls. PBS solution was used as a negative control and $\mathrm{H}_{2} \mathrm{O}_{2}(75 \mu \mathrm{mol} / \mathrm{l})$ as the positive damaging control. The comet assay was conducted according to the in vitro method of Gill et al. ${ }^{(33)}$. Within $48 \mathrm{~h}$ of completion of the assay, the cells were viewed using an epi-fluorescence microscope (Nikon epifluorescence; Nikon, Surrey, UK) at $400 \times$ magnification and 100 cells scored for DNA intensity in head and tail area using Komet 5 software

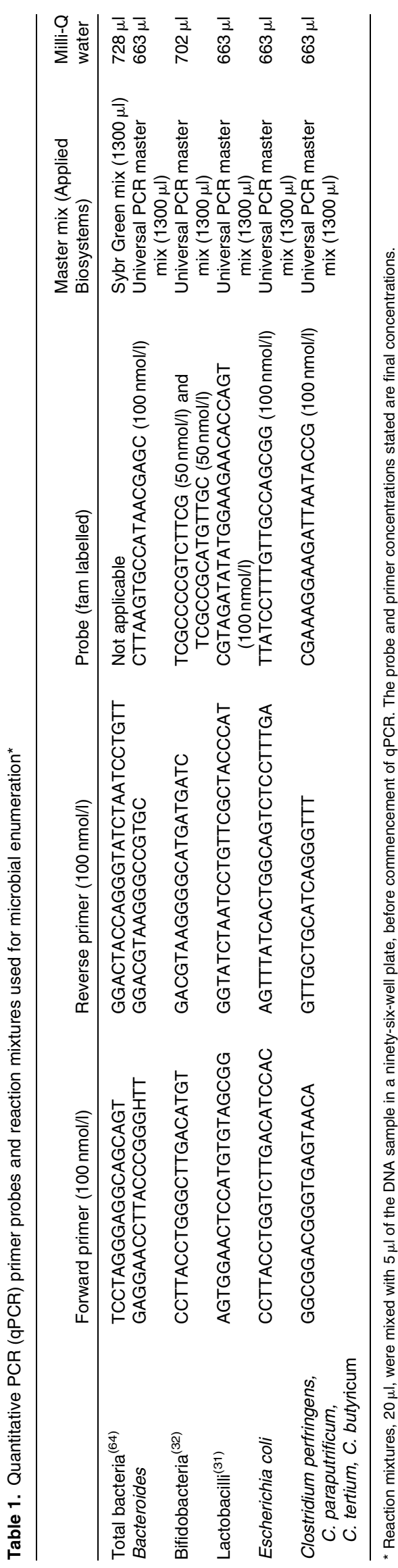


(Andor Technologies, Nottingham, UK). Results are expressed in terms of tail DNA intensity, which is the percentage of DNA that is able to migrate outside the general cell mass. The more the migration that occurs, the greater the DNA tail intensity and the greater the DNA damage.

\section{Three-stage continuous culture fermentation}

A second baseline sample of freshly voided faeces from three randomly selected volunteers was taken and used in three parallel three-stage continuous culture systems (adapted from Macfarlane \& Gibson $\left.{ }^{(34)}\right)$. The samples were diluted to a concentration of $20 \%(\mathrm{w} / \mathrm{v})$ in pre-reduced $0 \cdot 1 \mathrm{mmol} / \mathrm{l}, \mathrm{pH} 7 \cdot 4$, PBS solution, homogenised for $3 \mathrm{~min}$, and then $100 \mathrm{ml}$ of this faecal slurry added to each of three vessels of the three in vitro systems. The vessels were held at operating volumes of 280,300 and $300 \mathrm{ml}$ and $\mathrm{pH}$ values of $5 \cdot 5,6 \cdot 2$ and $6 \cdot 8$, respectively, representing the proximal, transverse and distal regions of the colon in terms of $\mathrm{pH}$, transit time and nutrient availability. Anaerobic conditions were established by the pumping of oxygen-free nitrogen gas $(15 \mathrm{ml} / \mathrm{min})$ through each vessel of the continuous culture system. The bacteria were allowed to establish in each of the vessels for $24 \mathrm{~h}$ before the medium feed pump was started.

The medium used was as described by Macfarlane \& Gibson $^{(34)}$. Continuous culture systems were conducted at a retention time of $36 \mathrm{~h}$. Samples were taken from the models after $13 \mathrm{~d}$, and SCFA profiles monitored; steady state was determined through stabilising of the SCFA and branched chain fatty acid concentrations over 3 consecutive days. Steady state was reached following a minimum of ten turnovers (15d) and the model was dosed with $4 \mathrm{~g}$ GOS, twice daily.

\section{SCFA analysis}

SCFA profiles were determined by GC as done previously by Pereira \& Gibson ${ }^{(35)}$.

\section{Statistical analysis}

By the use of a statistical power calculation, it was determined that at a significance level of $5 \%$ (two-sided), a log change of 0.33 bacterial numbers could be detected, at a power of $90 \%$, with thirty-nine volunteers. This calculation was based on the assumption that baseline standard deviation is $0 \cdot 42$, which was as observed by Tuohy et $a l^{(36)}$ in younger adults.

It was calculated that for the comet assay, using samples from five volunteers would enable detection of a $15 \%$ difference in tail DNA following treatment, at a probability of $93 \%$. This was based on the assumption that the withinsubject standard deviation of genotoxicity was $5 \%^{(32)}$.

Before analysis, bacteriology data were log transformed. Bacteriology, genotoxicity and SCFA data were analysed using paired-sample $t$ tests to compare the outcomes following consumption of the treatment and placebo preparations. Additionally, a general linear model was performed on the human subjects trial bacteriology data, using a post boc Tukey test to determine changes following consumption of the placebo and treatment preparations.

For assessing the influence of different factors, such as carbohydrate intake or BMI, volunteers were grouped accordingly, and the groups were split based on their medians. On these smaller groups, a paired $t$ test was conducted to assess the significance of changes post-placebo to post-treatment. When using these smaller groups ( $n$ 19), it was determined that at a significance level of 5\% (two-sided), a log change of 0.44 bacterial numbers could be detected, at a power of $90 \%$.

Results are reported as means with standard deviations. When the $P$-value was $<0 \cdot 05$, results were considered to be statistically significant. Minitab 14 (Lead Technologies Inc., Charlotte, NC, USA) was used for the statistical analysis.

\section{Results}

A dosage of $4 \mathrm{~g}$ GOS twice daily was very well tolerated, as there were no significant differences in stool consistency,

Table 2. Changes in faecal bacteriology in volunteers over 50 years undergoing 3-week placebo and 3-week galacto-oligosaccharides (GOS) intervention $(4 \mathrm{~g}$ twice daily)*

(Mean values and standard deviations, $n$ 37)

\begin{tabular}{|c|c|c|c|c|c|c|c|c|c|c|c|c|}
\hline & \multicolumn{6}{|c|}{ Placebo treatment } & \multicolumn{6}{|c|}{ GOS treatment } \\
\hline & \multicolumn{2}{|c|}{ Pre-placebo } & \multicolumn{2}{|c|}{ Post-placebo } & \multicolumn{2}{|c|}{ Placebo washout } & \multicolumn{2}{|c|}{ Pre-GOS } & \multicolumn{2}{|c|}{ Post-GOS } & \multicolumn{2}{|c|}{ GOS washout } \\
\hline & Mean & SD & Mean & SD & Mean & SD & Mean & SD & Mean & SD & Mean & SD \\
\hline \multicolumn{13}{|l|}{$\log _{10}$ CFU/g faeces } \\
\hline Total bacteria & $11 \cdot 70^{\mathrm{a}}$ & 0.30 & $11.80^{\mathrm{a}}$ & 0.27 & $11 \cdot 70^{\mathrm{a}}$ & 0.34 & $11 \cdot 80^{\mathrm{a}}$ & 0.20 & $11.90^{\mathrm{a}}$ & 0.24 & $11 \cdot 70^{\mathrm{a}}$ & 0.30 \\
\hline Bifidobacterium & $8 \cdot 87^{\mathrm{a}, \mathrm{b}}$ & 1.15 & $8.64^{\mathrm{a}}$ & 0.95 & $8.82^{a, b}$ & 0.83 & $8.86^{a, b}$ & 0.82 & $9 \cdot 16^{\mathrm{b}}$ & 1.09 & $8 \cdot 81^{a, b}$ & 1.06 \\
\hline Lactobacillus & $5 \cdot 85^{\mathrm{a}}$ & 0.64 & $5.78^{\mathrm{a}}$ & 0.61 & $5 \cdot 89^{\mathrm{a}}$ & 0.70 & $6 \cdot 05^{\mathrm{a}}$ & 0.74 & $5 \cdot 86^{\mathrm{a}}$ & 0.61 & $5.98^{\mathrm{a}}$ & 0.82 \\
\hline Escherichia coli & $6 \cdot 51^{a}$ & 1.36 & $6 \cdot 45^{\mathrm{a}}$ & $1 \cdot 24$ & $6 \cdot 51^{a}$ & 1.35 & $6 \cdot 61^{a}$ & 1.33 & $6 \cdot 64^{a}$ & $1 \cdot 23$ & $6 \cdot 30^{\mathrm{a}}$ & $1 \cdot 12$ \\
\hline Bacteroides & $10 \cdot 20^{\mathrm{a}, \mathrm{b}}$ & 0.67 & $9.89^{\mathrm{a}}$ & 0.66 & $10 \cdot 30^{a, b}$ & 0.51 & $10 \cdot 30^{\mathrm{b}}$ & 0.56 & $9 \cdot 98^{\mathrm{a}, \mathrm{b}}$ & 0.66 & $10 \cdot 20^{a, b}$ & 0.49 \\
\hline \multicolumn{13}{|l|}{$\mathrm{Log}_{10}$ cells/g faeces } \\
\hline Eubacterium rectales group & $9 \cdot 55^{\mathrm{a}}$ & 0.99 & $9.51^{a}$ & 0.66 & $9.59^{a}$ & 1.02 & $9.56^{a}$ & 0.37 & $9.68^{a}$ & 1.01 & $9.53^{a}$ & 0.31 \\
\hline Clostridium histolyticum group & $5 \cdot 59^{a}$ & 1.48 & $5.47^{\mathrm{a}}$ & 1.49 & $5 \cdot 47^{\mathrm{a}}$ & 1.55 & $5.52^{\mathrm{a}}$ & 1.51 & $5 \cdot 64^{\mathrm{a}}$ & 1.46 & $5.58^{\mathrm{a}}$ & 1.35 \\
\hline
\end{tabular}

CFU, colony-forming units.

${ }^{\mathrm{a}, \mathrm{b}}$ Mean values with unlike superscript letters within a row were significantly different for each treatment $(P<0.05)$

${ }^{*}$ Analysed by one-way ANOVA with Tukey's post hoc test. 
Table 3. Nutritional intake of volunteers over $24 \mathrm{~h}$, from data of 3 consecutive days and guideline daily amounts (GDA)

(Mean values and standard deviations, $n 21$ for women and $n 18$ for men)

\begin{tabular}{|c|c|c|c|c|c|c|}
\hline & \multicolumn{4}{|c|}{ Nutritional intake } & & \\
\hline & \multicolumn{2}{|c|}{ Men } & \multicolumn{2}{|c|}{ Women } & \multicolumn{2}{|c|}{$\mathrm{GDA}^{*}$} \\
\hline & Mean & SD & Mean & SD & Men & Women \\
\hline Energy (kJ/d) & 6760 & 2000 & 6370 & 2200 & 10467 & 8373.6 \\
\hline Protein $(\mathrm{g} / \mathrm{d})$ & 78 & 34 & 72 & 37 & 55 & 45 \\
\hline Carbohydrate $(\mathrm{g} / \mathrm{d})$ & 206 & 74 & 200 & 81 & 300 & 230 \\
\hline Fat $(g / d)$ & 53 & 27 & 49 & 23 & 95 & 70 \\
\hline Saturated fat $(\mathrm{g} / \mathrm{d})$ & 16 & 11 & 14 & 8 & 30 & 20 \\
\hline Fibre (g/d) & 12 & 6 & 12 & 4 & 24 & 24 \\
\hline Added sugar (g/d) & 29 & 27 & 34 & 32 & 120 & 90 \\
\hline Salt (g/d) & $7 \cdot 2$ & 3 & 6 & 3 & 6 & 6 \\
\hline $\mathrm{Fe}(\mathrm{g} / \mathrm{d})$ & 15 & 13 & 13 & 9 & NS & NS \\
\hline
\end{tabular}

NS, not specified.

${ }^{*}$ Nutritional intake guide as published by the Institute of Grocery Distribution ${ }^{(65)}$.

intestinal bloating, abdominal discomfort, flatulence severity and frequency during GOS and control treatments (data not shown). Markers of mood remained the same throughout the two treatment periods. It was confirmed that there was no carry-over from the first leg of the crossover study by statistical evaluation using an ANOVA with a post boc Tukey test, as there were no significant differences regarding the sequence of the placebo or GOS treatments for all of the factors analysed within the study.

Prebiotic treatment led to significantly more faecal bifidobacteria (9.16 (SD 1.09) $\log _{10}$ colony-forming units (CFU)/g) as compared to the placebo: (8.64 (SD 0.95) $\log _{10} \mathrm{CFU} / \mathrm{g}$ ) $(P=0.024$ - Tukey test) (Table 2$)$.

Four Clostridium species - C. perfringens, C. paraputrificum, C. tertium and C. butyricum - were enumerated by quantitative PCR; however, they were found to be below the limit of detection $(\log 4.2 \mathrm{CFU} / \mathrm{g})$; therefore, these are not included in the results.

The bifidobacterial increase following GOS consumption differed between men and women. With men, 0.32 (SD 1.23) $\log _{10} \mathrm{CFU} / \mathrm{g}$ more bifidobacteria were observed following intervention ( $n$ 16); with women, 0.67 (SD 1.16) $\log _{10} \mathrm{CFU} / \mathrm{g}$ more bifidobacteria were observed ( $n$ 21). The bifidogenic response was not significant in the men $(P=0.31)$, but it was significant in the women $(P=0 \cdot 015)$ (data not shown).

The impact of BMI on the bifidogenic effects was assessed. Individuals under BMI $25 \mathrm{~kg} / \mathrm{m}^{2}$ had significantly more bifidobacteria after GOS consumption (9.20 (SD 0.75) $\log _{10} \mathrm{CFU} / \mathrm{g}$ ), relative to placebo (8.74 (SD 1.00) $\log _{10} \mathrm{CFU} / \mathrm{g} ; \quad P=0.05$; $n$ 24, fourteen females and ten males), while those over BMI $25 \mathrm{~kg} / \mathrm{m}^{2}$ did not (9.08 (sD 0.59) $\log _{10}$ CFU/g compared to placebo 8.45 (SD $1 \cdot 26$ ) $\log _{10} \mathrm{CFU} / \mathrm{g} ; P=0 \cdot 12 ; n 13$, seven females and six males) (data not shown).

Compared to the guideline daily amounts, the average nutritional intake of the volunteers was much lower for total energy and carbohydrate consumption, but was greater for protein (Table 3). The responses of volunteers ingesting more than the median of $200 \mathrm{~g}$ carbohydrate daily differed from those who ate less. In those eating more than $200 \mathrm{~g}$ carbohydrate daily, there were 0.28 (SD 1.44) $\log _{10} \mathrm{CFU} / \mathrm{g}$ more bifidobacteria following GOS intervention $(P=0.46$; $n 15$, eight females and seven males), and in those who ate less, there were 0.68 (SD 0.99) $\log _{10} \mathrm{CFU} / \mathrm{g}$ more bifidobacteria ( $P=0.0039 ; n 22$, thirteen females and nine males), relative to placebo. The opposite was observed with those eating more protein. Those eating more than the median of $70 \mathrm{~g}$ protein daily had 0.65 (SD 1.12) $\log _{10}$ CFU/g more bifidobacteria following GOS intervention ( $P=0.025 ; n$ 19, twelve females and seven males), and those ingesting less had 0.40 (SD 1.26) $\log _{10} \mathrm{CFU} / \mathrm{g}$ more relative to placebo, which was not statistically significant $(P=0 \cdot 18 ; n 18$, nine females and nine males) (data not shown).

From the comet assay, tail DNA intensity ranged from 9.5 to $76 \cdot 5 \%(35 \cdot 2(19 \cdot 1) \%)$. Out of the thirty-seven volunteers, ten had a tail DNA intensity of $<50 \%$, five of which were $<30 \%$. The average tail DNA intensity of the three smokers was $23.9 \%$ (range $19 \cdot 3-27 \cdot 2$; SD $4.0 \%$ ). The comet assay was conducted on all samples from the five volunteers with the highest tail DNA intensity (all non-smokers).

There was variation in faecal water genotoxicity of all the volunteers (Table 4). Changes in genotoxicity did not always coincide with GOS treatment; however, with volunteers A, C and $\mathrm{E}$, it did. A decline was seen before the treatment period for volunteer B and genotoxicity levels of volunteer

Table 4. Faecal water genotoxicity changes in volunteers over 50 years undergoing 3-week placebo and 3-week galacto-oligosaccharides (GOS) intervention (4 $\mathrm{g}$ twice daily) ${ }^{*}$

(Mean values and standard deviations, $n 3$ from screening with three technical replications, indicating assay variability)

\begin{tabular}{|c|c|c|c|c|c|c|c|c|c|c|c|c|}
\hline \multirow[b]{2}{*}{ Volunteers } & \multicolumn{2}{|c|}{ Pre-trial† } & \multicolumn{2}{|c|}{$\begin{array}{c}\text { Pre- } \\
\text { treatment } 1 \dagger\end{array}$} & \multicolumn{2}{|c|}{$\begin{array}{l}\text { Post- } \\
\text { treatment } 1 \dagger\end{array}$} & \multicolumn{2}{|c|}{$\begin{array}{c}\text { Treatment } 1 \\
\text { washout } †\end{array}$} & \multicolumn{2}{|c|}{$\begin{array}{c}\text { Post- } \\
\text { treatment } 2 \dagger\end{array}$} & \multicolumn{2}{|c|}{$\begin{array}{c}\text { Treatment } 2 \\
\text { washout } †\end{array}$} \\
\hline & Mean & SD & Mean & $S D$ & Mean & SD & Mean & SD & Mean & SD & Mean & SD \\
\hline A & $54 \cdot 7$ & $8 \cdot 8$ & $62 \cdot 2$ & $13 \cdot 0$ & $49 \cdot 8 \ddagger$ & $10 \cdot 8$ & $42 \cdot 4$ & $12 \cdot 3$ & $32 \cdot 1$ & $3 \cdot 8$ & $29 \cdot 1$ & $6 \cdot 5$ \\
\hline B & $76 \cdot 5$ & $14 \cdot 2$ & $52 \cdot 1$ & $7 \cdot 4$ & $60 \cdot 7$ & $5 \cdot 1$ & $16 \cdot 2$ & 3.4 & $45.4 \ddagger$ & $3 \cdot 1$ & $45 \cdot 6$ & 11.0 \\
\hline C & $68 \cdot 3$ & 0.5 & $15 \cdot 2$ & $2 \cdot 1$ & $24 \cdot 2$ & $6 \cdot 6$ & $24 \cdot 8$ & $1 \cdot 3$ & $8 \cdot 7 \ddagger$ & $4 \cdot 3$ & $6 \cdot 2$ & 1.5 \\
\hline D & $75 \cdot 9$ & 1.0 & $76 \cdot 7$ & $6 \cdot 0$ & $82 \cdot 7 \ddagger$ & 4.9 & $82 \cdot 8$ & 1.9 & $64 \cdot 3$ & 11.5 & $73 \cdot 1$ & 2.8 \\
\hline$E$ & $68 \cdot 3$ & $17 \cdot 0$ & 61.9 & $13 \cdot 0$ & $16 \cdot 4 \ddagger$ & 0.3 & $25 \cdot 5$ & $7 \cdot 0$ & $36 \cdot 0$ & $9 \cdot 3$ & $21 \cdot 4$ & $7 \cdot 0$ \\
\hline
\end{tabular}

* Samples were analysed throughout the trial from five volunteers $(A-E)$.

$\dagger$ Percentage of tail DNA.

$\ddagger$ The highlighted values indicate the faecal water genotoxicity post-GOS treatment. 
D remained high throughout. The genotoxicity results showed no significant changes.

\section{Multiple-stage continuous culture systems}

Following GOS intervention within the continuous culture systems (Table 5), significant increases in bifidobacteria were identified in the three vessels $(P=0.033 ; 0.033 ; 0.004$, respectively, $t$ test). In vessel 1 , Lactobacillus significantly increased following the addition of GOS to the system $(P=0 \cdot 001)$. Within vessel 2, the number of Escherichia coli significantly declined $(P=0 \cdot 026)$.

There was significantly more butyrate in all three vessels of the continuous culture system following dosing with GOS (Table 6). In vessel 3 , significant reductions in propionate $(P=0.008)$ and in the branched chain fatty acid iso-valerate ( $P=0.008)$ were observed following GOS dosing.

\section{Discussion}

Intervention with prebiotics and synbiotics in a maturing population has previously been observed to offer potential benefits ${ }^{(22,37-39)}$. The present study used in vitro models alongside a prebiotic intervention human subjects trial. This study has utilised modern molecular techniques for microbial enumeration $^{(40)}$, to provide a more quantifiably accurate approach to plating ${ }^{(41)}$

A significant bifidogenic effect was observed following consumption of $4 \mathrm{~g}$ GOS twice daily, for this cohort of men and women over 50 years of age. Moreover, the increase was highest in subjects with the lowest basal levels of bifidobacteria, which corresponds well with previous studies ${ }^{(21-24)}$. A difference of $0.5 \mathrm{log}$ was observed between the placebo and the prebiotic; such a change is considered a major shift in the gut microbiota towards a potentially healthier composition ${ }^{(42)}$. Unexpectedly, the bifidobacteria increase in the faecal microbiota of men was not significant $(P=0.31)$; however, a 0.3 $\log _{10}$ CFU/g increase was observed.

The placebo product contained about $4 \mathrm{~g}$ less simple sugars, as compared to the GOS juice preparation $/ 250 \mathrm{ml}$. This, however, is unlikely to make an impact on the results of the present study, as these sugars are likely to be digested in the upper gastrointestinal tract.

The lower-than-guideline daily amounts intake of energy and carbohydrate of the volunteers could be a reflection of inaccurate recording, or dietary modification over the days of diary entries. Volunteers were asked to maintain their normal diets throughout the study and to keep the diary recordings over 3 consecutive days, as this could help combat dietary alterations (as an individual is less likely to modify their diet for 3 consecutive days). There was a higher-than-guideline daily amounts intake of protein. A high protein intake is generally associated with a negative impact on the gut microbiota ${ }^{(3,43)}$.

It has previously been observed that increased carbohydrate consumption leads to more carbohydrate reaching the colon $^{(44)}$. In the present study, those consuming more carbohydrate were also consuming more fibre $(P=0.013 ; n 19$, 
Table 6. SCFA profiles as determined by GC in in vitro continuous culture systems using galacto-oligosaccharides (GOS) as a substrate at $4 \mathrm{~g}$ twice daily

(Mean values and standard deviations, $n 3$ from three continuous culture systems; three different baseline volunteer faecal samples provided the bacterial inoculum

\begin{tabular}{|c|c|c|c|c|c|c|c|c|c|c|c|c|}
\hline & \multicolumn{4}{|c|}{ Vessel 1} & \multicolumn{4}{|c|}{ Vessel 2} & \multicolumn{4}{|c|}{ Vessel 3} \\
\hline & \multicolumn{2}{|c|}{$\begin{array}{l}\text { Steady } \\
\text { state } 1 \dagger\end{array}$} & \multicolumn{2}{|c|}{$\begin{array}{l}\text { Steady } \\
\text { state } 2 \ddagger\end{array}$} & \multicolumn{2}{|c|}{$\begin{array}{l}\text { Steady } \\
\text { state } 1 \dagger\end{array}$} & \multicolumn{2}{|c|}{$\begin{array}{l}\text { Steady } \\
\text { state } 2 \ddagger\end{array}$} & \multicolumn{2}{|c|}{$\begin{array}{l}\text { Steady } \\
\text { state } 1 \dagger\end{array}$} & \multicolumn{2}{|c|}{$\begin{array}{c}\text { Steady } \\
\text { state } 2 \ddagger\end{array}$} \\
\hline & Mean & SD & Mean & SD & Mean & SD & Mean & SD & Mean & SD & Mean & SD \\
\hline Acetate $(\mathrm{mmol} / \mathrm{l})$ & 32.9 & 4.4 & 32.4 & $2 \cdot 7$ & $32 \cdot 1$ & 3.9 & 33.6 & 0.9 & $32 \cdot 7$ & 3.4 & $35 \cdot 6$ & 4.0 \\
\hline Propionate $(\mathrm{mmol} / \mathrm{l})$ & 20.7 & $2 \cdot 7$ & $19 \cdot 3$ & 1.1 & 21.9 & $2 \cdot 3$ & $18 \cdot 1$ & 0.6 & 23.8 & 3.0 & $18 \cdot 9$ & 3.5 \\
\hline Iso-butyrate $(\mathrm{mmol} / \mathrm{l})$ & $3 \cdot 2$ & $2 \cdot 3$ & $2 \cdot 4$ & 1.5 & 3.7 & $1 \cdot 3$ & $2 \cdot 4$ & 0.9 & $4 \cdot 3$ & 1.0 & $2 \cdot 9$ & 0.3 \\
\hline Butyrate $(\mathrm{mmol} / \mathrm{l})$ & $26 \cdot 6$ & 3.0 & $36 \cdot 1^{*}$ & $4 \cdot 7$ & $27 \cdot 4$ & $5 \cdot 1$ & $39 \cdot 0^{*}$ & $5 \cdot 2$ & $29 \cdot 3$ & $6 \cdot 1$ & $44 \cdot 0^{*}$ & 5.0 \\
\hline Iso-valerate $(\mathrm{mmol} / \mathrm{l})$ & 4.5 & $2 \cdot 2$ & $3 \cdot 0$ & $1 \cdot 7$ & $5 \cdot 3$ & 0.8 & $3 \cdot 7$ & $1 \cdot 2$ & $5 \cdot 9$ & 0.5 & $4 \cdot 3^{\star}$ & 0.6 \\
\hline Valerate $(\mathrm{mmol} / \mathrm{l})$ & 3.6 & 3.9 & $3 \cdot 7$ & $2 \cdot 4$ & $5 \cdot 2$ & 2.4 & $3 \cdot 8$ & $2 \cdot 0$ & $6 \cdot 1$ & 1.9 & 4.0 & 1.3 \\
\hline Caproate $(\mathrm{mmol} / \mathrm{l})$ & $2 \cdot 7$ & 3.5 & 2.4 & 2.5 & $3 \cdot 1$ & $2 \cdot 8$ & $3 \cdot 0$ & $2 \cdot 8$ & $3 \cdot 1$ & $2 \cdot 6$ & 3.2 & $2 \cdot 6$ \\
\hline
\end{tabular}

* Mean values were significantly different from steady state 1 (pre-treatment; $P \leq 0.05$ ).

$\dagger$ Steady state before treatment.

$\ddagger$ Steady state following GOS treatment.

twelve females and seven males). The bifidogenic effect in those eating $<200 \mathrm{~g}$ of carbohydrate daily, while not in those eating more, was therefore possibly a consequence of greater carbohydrate yields reaching the colon in the latter group. Previous studies on overweight and obese individuals have shown a reduced intake of carbohydrate to be accompanied by a decrease in bifidobacterial numbers ${ }^{(45,46)}$. Lower bifidobacteria levels were not observed in the present study; however, it seems plausible that carbohydrate persisting to the large intestine non-selectively influences the fermentation characteristics within ${ }^{(47)}$. As a consequence, additional fibre was not able to have the same magnitude of effect in $>200 \mathrm{~g} / \mathrm{d}$ carbohydrate consumers as in those consuming less.

It was observed that a significant bifidogenic effect occurred with greater protein consumption $(>70 \mathrm{~g} / \mathrm{d} ; P=0.026)$, while the effect was not significant when less protein was consumed. Therefore, it is likely that more protein was reaching the distal colonic regions of these individuals ${ }^{(48)}$, and was available for fermentation by proteolytic organisms. An increase in carbohydrate through prebiotic intake may therefore have had a greater impact on the nature of fermentation occurring within; and subsequently exerted a greater impact on the gut microbiota. As GOS acts in a selective way, these effects may be particularly on beneficial groups such as bifidobacteria. It therefore seems that GOS consumption led to an altered fermentation profile, particularly when higher protein levels were consumed, to a potentially more beneficial one. Duncan et $a l .^{(46)}$ have previously observed that in obese volunteers, diets rich in protein and low in carbohydrate lead to reduced numbers of bifidobacteria. Thus prebiotic intervention may have a greater impact in such individuals. The greater impact of prebiotics was confirmed in the present study.

When looking at the bifidogenic effect in terms of BMI, those under $25 \mathrm{~kg} / \mathrm{m}^{2}$ saw a significantly bifidogenic effect, while those of the higher BMI group did not. An impact of the microbiota on metabolism has been previously observed (Cani \& Delzenne $\left.{ }^{(49)}\right)$. Thus such differences may also influence the effect of a prebiotic. Future assessment of prebiotics as to whether a higher dose is required for those of a greater BMI may be of benefit.

Faecal water genotoxicity provides information on the carcinogenic potential within the distal colonic content ${ }^{(50,51)}$. This provides an indication of how diet may affect carcinogenesis risk $^{(52)}$. Cigarette smokers were not monitored throughout the study due to differences in the way they may respond to treatments ${ }^{(53)}$. The faecal water data were inconclusive, as no significant changes were determined; this may be partially due to the variability of genotoxicity results obtained, and it seems likely that other lifestyle factors could be responsible for such changes ${ }^{(53)}$. Indeed, the work of Pearson et al. ${ }^{(52)}$ has shown that many studies indicate such variations. The present study allowed volunteers to continue their normal dietary and alcohol habits, although such levels of faecal water variation have also been observed in volunteers with controlled diets $^{(54)}$. Further work on a greater number of individuals with higher baseline genotoxicity levels may better enable changes to be determined.

The use of an in vitro model provides a tool for looking at potential changes in other colonic areas, where bacterial growth at different $\mathrm{pH}$, transit times and nutrient availability can be assessed. SCFA, which would normally be absorbed, can also be assessed, thus giving more of an indication of the effects of dietary intervention on SCFA levels. The in vitro data show significant bifidogenic effects in all three vessels of the continuous culture system, re-emphasising the ability of GOS to stimulate this potentially beneficial group of bacteria. The increase of lactobacilli observed in vessel 1 of the model is a potentially positive change, as this group is largely associated with positive health outcomes. Enhanced lactobacilli numbers following GOS consumption have previously been observed in adult volunteers ${ }^{(25,26)}$. The group $E$. coli includes some opportunistic pathogens, and subsequently the decrease in this bacterial group in vessel 2 is also considered to be potentially positive. A decrease in $E$. coli in the presence of prebiotics has also been observed by Sharp et $a l .{ }^{(55)}$; such changes could be potentially caused by the inhibitory properties of bifidobacteria ${ }^{(56)}$. 
A significant increase in the amount of butyrate in all three vessels of the continuous culture system provides further evidence of persistence. Bifidobacteria do not produce butyrate; however, Belenguer et al. ${ }^{(57)}$ observed that certain known butyrate producers (Eubacterium hallii and Anaerostipes caccae) utilise lactate from Bifidobacterium adolescentis during butyrate production, indicating the existence of a cross-feeding pathway. In addition, this observed butyrate stimulation could potentially result from an increase in acetate production, as acetate is utilised by some key butyrate-producing bacteria, such as $F$. prausnitzii and Roseburia spp. ${ }^{(58)}$. Butyrate is the preferred energy source for colonocytes ${ }^{(59,60,61)}$ and has been linked to anti-cancer activities and inducing of apoptosis in damaged cells ${ }^{(62)}$. Similar increased concentrations of butyrate has been seen to lead to enhanced activities of butyrate as an inhibitor of histone deacetylation, hence assisting the regulation of the cell-cycle events ${ }^{(63)}$. Therefore, such an increase is potentially beneficial to the host.

Branched chain fatty acids are indicative of protein fermentation $^{(2)}$, and thus their decline indicates that less proteolysis is occurring. Overall, it could be seen that the SCFA concentrations increased following GOS treatment, and that branched chain fatty acid concentrations decreased; thus a more saccharolytic environment was achieved. Therefore it seems, in vitro, GOS caused a distal shift in fermentation, to an environment considered more beneficial to the host.

Overall, the combined in vitro and in vivo results of the present study show bifidogenic and saccharolytic effects and the potential to act within more distal regions of the gastrointestinal tract. This indicates that GOS can be used as a selective ingredient to beneficially affect gut bacterial composition and to reduce the risk factors associated with shifts in the colonic microbiota and fermentation resultant of ageing. Consequently, GOS could promote well-being in a more mature population.

\section{Acknowledgements}

This project was made possible by the financial support of a Biotechnology and Biological Sciences Research Council, FrieslandCampina - research case studentship award. The product tested within this research was provided by the case funders for this project. E. G. H. M. v. d. H. and M. H. W. K. both worked as employees for the case funders. G. E. W., K. M. T., R. A. R. and G. R. G. have no conflicts of interest. G. E. W., K. M. T., G. R. G., R. A. R. and E. G. H. M. v. d. H. designed the research and were involved in the preparation of the manuscript; G. E. W. conducted the research; M. H. W. K. developed the quantitative PCR technique and associated probes used in this research. G. E. W. analysed the data; G. E. W., G. R. G. and E. G. H. M. v. d. H. wrote the paper. G. E. W. had primary responsibility for the final content. All the authors read and approved the final manuscript.

\section{References}

1. Macfarlane GT, Macfarlane S \& Gibson GR (1998) Validation of a three-stage compound continuous culture system for investigating the effect of retention time on the ecology and metabolism of bacteria in the human colonic microbiota. Microb Ecol Health Dis 35, 180-187.

2. Macfarlane GT, Gibson GR \& Cummings JH (1992) Comparison of fermentation reactions in different regions of the human colon. J Appl Bacteriol 72, 57-64.

3. Bajka BH, Clarke JM, Cobiac L, et al. (2008) Butyrylated starch protects colonocyte DNA against dietary proteininduced damage in rats. Carcinogenesis 29, 2169-2174.

4. Lin HC \& Visek WJ (1991) Colon mucosal cell damage by ammonia in rats. $J$ Nutr 121, 887-893.

5. Macfarlane S \& Macfarlane GT (1995) Proteolysis and amino acid fermentation. In Human Colonic Bacteria: Role in Nutrition, Physiology and Pathology, pp. 75-100 [GR Gibson and GT Macfarlane, editors]. Boca Raton, FL: CRC Press.

6. Woodmansey EJ (2007) Intestinal bacteria and ageing. J Appl Microbiol 102, 1178-1186.

7. Mäkivuokko H, Tiihonen K, Tynkkynen S, et al. (2010) The effect of age and non-steroidal anti-inflammatory drugs on human intestinal microbiota composition. Br J Nutr $\mathbf{1 0 3}$ 227-234

8. Mueller S, Saunier K, Hanisch C, et al. (2006) Differences in fecal microbiota in different European study populations in relation to age, gender, and country: a cross-sectional study. Appl Environ Microbiol 72, 1027-1033.

9. Rajilic-Stojanovic M, Heilig HGHJ, Molenaar D, et al. (2009) Development and application of the human intestinal tract chip, a phylogenetic microarray: analysis of the universally conserved phylotypes in the abundant microbiota of young and elderly adults. Environ Microbiol 11, 1736-1751.

10. Hopkins MJ, Sharp R \& Macfarlane GT (2001) Age and disease related changes in intestinal bacterial populations assessed by cell culture, $16 \mathrm{~S}$ rRNA abundance, and community cellular fatty acid profiles. Gut 48, 198-205.

11. Hopkins MJ \& Macfarlane GT (2002) Changes in predominant bacterial populations in human faeces with age and with Clostridium difficile infection. I Med Microbiol 51, 448-454.

12. Zwielehner J, Liszt K, Handschur M, et al. (2009) Combined PCR-DGGE fingerprinting and quantitative-PCR indicates shifts in fecal population sizes and diversity of Bacteroides, bifidobacteria and Clostridium cluster IV in institutionalized elderly. Exp Gerontol 44, 440-446.

13. Biagi E, Nylund L, Candela M, et al. (2010) Through ageing, and beyond: gut microbiota and inflammatory status in seniors and centenarians. PLOS ONE 5, e10667.

14. Lay C, Rigottier-Gois L, Holmstrøm K, et al. (2005) Colonic microbiota signatures across five northern European countries. Appl Environ Microbiol 71, 4153-4145.

15. Claesson M, Cusack S, O'Sullivan O, et al. (2011) Composition, variability, and temporal stability of the intestinal microbiota of the elderly. Proc Natl Acad Sci U S A. $\mathbf{1 0 8}$ (Suppl. 1), 4586-4591.

16. Cai J, Clark J, Croft S, et al. (2008) Indications of Public Health in the English Regions: Older People. York: Association of Public Health Observatories.

17. Woodmansey EJ, McMurdo ME, Macfarlane GT, et al. (2004) Comparison of compositions and metabolic activities of fecal microbiotas in young adults and in antibiotic-treated and non-antibiotic-treated elderly subjects. Appl Environ Microbiol 70, 6113-6122.

18. Bartosch S, Fite A, Macfarlane GT, et al. (2004) Characterization of bacterial communities in feces from healthy elderly volunteers and hospitalized elderly patients by using 
real-time PCR and effects of antibiotic treatment on the fecal microbiota. Appl Environ Microbiol 70, 3575-3581.

19. Saunier K \& Doré J (2002) Gastrointestinal tract and the elderly: functional foods, gut microflora and healthy ageing. Dig Liver Dis 34, 19-24.

20. Gibson GR, Scott KP, Rastall RA, et al. (2010) Dietary prebiotics: current status and new definition. FST Bull 7, 1-19.

21. Silk DBA, Davis A, Vulevic J, et al. (2009) Clinical trial: the effect of a trans-galactooligosaccharide prebiotic on faecal microbiota and symptoms in irritable bowel syndrome. Aliment Pharmacol Ther 29, 508-518.

22. Vulevic J, Drakoularakou A, Yaqoob P, et al. (2008) Modulation of the fecal microflora profile and immune function by a novel trans-galactooligosaccharide mixture (B-GOS) in healthy elderly volunteers. Am J Clin Nutr 88, 1438-1446.

23. Depeint F, Tzortzis G, Vulevic J, et al. (2008) Prebiotic evaluation of a novel galactooligosaccharide mixture produced by the enzymatic activity of Bifidobacterium bifidum NCIMB 41171, in healthy humans: a randomized, double-blind, crossover, placebo-controlled intervention study. Am J Clin Nutr 87, 785-791.

24. Bouhnik Y, Raskine L, Simoneau G, et al. (2004) The capacity of nondigestible carbohydrates to stimulate fecal bifidobacteria in healthy humans: a double-blind, randomized, placebo-controlled, parallel-group, dose-response relation study. Am J Clin Nutr 80, 1658-1664.

25. Ito M, Deguchi Y, Miyamori A, et al. (1990) Effects of administration of galacto-oligosaccharides on the human faecal microflora, stool weight and abdominal sensation. Microb Ecol Health Dis 3, 285-292.

26. Gopal PK, Prasad J \& Gill HS (2003) Effects of the consumption of Bifidobacterium lactis HN019 (DR10TM) and galactooligosaccharides on the microflora of the gastrointestinal tract in human subjects. Nutr Res 23, 1313-1328.

27. Fanaro S, Marten B, Bagna R, et al. (2009) Galacto-oligosaccharides are bifidogenic and safe at weaning: a double-blind randomized multicenter study. J Pediatr Gastroenterol Nutr 48, 82-88.

28. Probert HM, Apajalahti JH, Rautonen N, et al. (2004) Polydextrose, lactitol, and fructo-oligosaccharide fermentation by colonic bacteria in a three-stage continuous culture system. Appl Environ Microbiol 70, 4505-4511.

29. Franks AH, Harmsen HJM, Raangs GC, et al. (1998) Variations of bacterial populations in human feces measured by fluorescent in situ hybridization with group-specific 16S rRNA-targeted oligonucleotide probes. Appl Environ Microbiol 64, 3336-3345.

30. Ritalahti KM, Amos BK, Sung Y, et al. (2006) Quantitative PCR targeting 16S rRNA and reductive dehalogenase genes simultaneously monitors multiple Dehalococcoides strains. Appl Environ Microbiol 72, 2765-2774

31. Nauta A, van den Heuvel EGHM \& Veurink JH, et al. (2008) Lactobacillus - the invention provides means and methods for detecting, amplifying, quantifying and/or isolating nucleic acid of at least one Lactobacillus organism. European patent EP 1997906 A1.

32. Nauta A, van den Heuvel EGHM \& Veurink JH, et al. (2008) Bifidobacterium - the invention provides means and methods for detecting, amplifying, quantifying and/or isolating nucleic acid of at least one member of Bifidobacterium. European patent EP 1997907.

33. Gill CI, Haldar S, Porter S, et al. (2004) The effect of cruciferous and leguminous sprouts on genotoxicity, in vitro and in vivo. Cancer Epidemiol Biomarkers Prev 13, 1199-1205.

34. Macfarlane GT \& Gibson GR (1997) Carbohydrate fermentation, energy transduction, and gas metabolism in the human large intestine. In Gastrointestinal Microbiology, pp. 269-318 [RI Mackie and BA White, editors]. London: Chapman and Hall.

35. Pereira DI \& Gibson GR (2002) Cholesterol assimilation by lactic acid bacteria and bifidobacteria isolated from the human gut. Appl Environ Microbiol 68, 4689-4693.

36. Tuohy KM, Kolida S, Lustenberger AM, et al. (2001) The prebiotic effects of biscuits containing partially hydrolysed guar gum and fructo-oligosaccharides - a human volunteer study. Br J Nutr 86, 341-348.

37. Bouhnik Y, Achour L, Paineau D, et al. (2007) Four-week short chain fructo-oligosaccharides ingestion leads to increasing fecal bifidobacteria and cholesterol excretion in healthy elderly volunteers. Nutr J 6, 42-49.

38. Bartosch S, Woodmansey EJ, Paterson JC, et al. (2005) Microbiological effects of consuming a synbiotic containing Bifidobacterium bifidum, Bifidobacterium lactis, and oligofructose in elderly persons, determined by real-time polymerase chain reaction and counting of viable bacteria. Clin Infect Dis 40, 28-37.

39. Surakka A, Kajander K, Rajilić-Stojanović M, et al. (2009) Yoghurt containing galactooligosaccharides facilitates defecation among elderly subjects and selectively increases the number of bifidobacteria. Int J Prob Preb 4, 65-74.

40. Wilson KH \& Blitchington RB (1996) Human colonic biota studied by ribosomal DNA sequence analysis. Appl Environ Microbiol 62, 2273-2278.

41. Apajalahti JH, Kettunen A, Nurminen PH, et al. (2003) Selective plating underestimates abundance and shows differential recovery of bifidobacterial species from human feces. Appl Environ Microbiol 69, 5731-5735.

42. Kolida S \& Gibson GR (2007) Prebiotic capacity of inulintype fructans. J Nutr 137, (Suppl. 11), 2503S-2506S.

43. Toden S, Bird AR, Topping DL, et al. (2007) Dose-dependent reduction of dietary protein-induced colonocyte DNA damage by resistant starch in rats correlates more highly with caecal butyrate than with other short chain fatty acids. Cancer Biol Ther 6, 253-258.

44. Langkilde AM, Champ M \& Andersson H (2002) Effects of high-resistant-starch banana flour (RS(2)) on in vitro fermentation and the small-bowel excretion of energy, nutrients, and sterols: an ileostomy study. Am J Clin Nutr 75, 104-111.

45. Brinkworth GD, Noakes M, Clifton PM, et al. (2009) Comparative effects of very low-carbohydrate, high-fat and high-carbohydrate, low-fat weight-loss diets on bowel habit and faecal short-chain fatty acids and bacterial populations. Br J Nutr 101, 1493-1502.

46. Duncan SH, Belenguer A, Holtrop G, et al. (2007) Reduced dietary intake of carbohydrates by obese subjects results in decreased concentrations of butyrate and butyrate-producing bacteria in feces. Appl Environ Microbiol 73, 1073-1078.

47. Muir JG \& O'Dea K (1993) Validation of an in vitro assay for predicting the amount of starch that escapes digestion in the small intestine of humans. Am J Clin Nutr 57, 540-546.

48. Evenepoel P, Claus D, Geypens B, et al. (1999) Amount and fate of egg protein escaping assimilation in the small intestine of humans. Am J Physiol 277, G935-G943.

49. Cani PD \& Delzenne NM (2009) The role of the gut microbiota in energy metabolism and metabolic disease. Curr Pharm Des 15, 1546-1558.

50. Benassi B, Leleu R, Bird T, et al. (2007) Cytokinesis-block micronucleus cytome assays for the determination of genotoxicity and cytotoxicity of cecal water in rats and fecal water in humans. Cancer Epidemiol Biomarkers Prev 16, 2676-2680. 
51. Singh NP, McCoy MT, Tice RR, et al. (1988) A simple technique for quantitation of low levels of DNA damage in individual cells. Exp Cell Res 175, 184-191.

52. Pearson JR, Gill CI \& Rowland IR (2009) Diet, fecal water, and colon cancer-development of a biomarker. Nutr Rev 67, 509-526.

53. Glei M, Habermann N, Osswald K, et al. (2005) Assessment of DNA damage and its modulation by dietary and genetic factors in smokers using the Comet assay: a biomarker model. Biomarkers 10, 203-217.

54. Oßwald K, Becker TW, Grimm M, et al. (2000) Inter- and intra-individual variation of faecal water - genotoxicity in human colon cells. Mutat Res 472, 59-70.

55. Sharp R, Fishbain S \& Macfarlane GT (2001) Effect of shortchain carbohydrates on human intestinal bifidobacteria and Escherichia coli in vitro. J Med Microbiol 50, 152-160.

56. Gibson GR \& Wang X (1994) Regulatory effects of bifidobacteria on the growth of other colonic bacteria. J Appl Bacteriol 77, 412-420

57. Belenguer A, Duncan SH, Calder AG, et al. (2006) Two routes of metabolic cross-feeding between Bifidobacterium adolescentis and butyrate-producing anaerobes from the human gut. Appl Environ Microbiol 72, 3593-3599.

58. Duncan SH, Barcenilla A, Stewart CS, et al. (2002) Acetate utilization and butyryl coenzyme A (CoA):acetate-CoA transferase in butyrate-producing bacteria from the human large intestine. Appl Environ Microbiol 68, 5186-5190.

59. Roediger WE (1980) Role of anaerobic bacteria in the metabolic welfare of the colonic mucosa in man. Gut $\mathbf{2 1}$, 793-798.

60. Hill MJ (1995) Introduction: dietary fibre, butyrate and colorectal cancer. Eur J Cancer Prev 4, 341-343.

61. Singh B, Halestrap AP \& Paraskeva C (1997) Butyrate can act as a stimulator of growth or an inducer of apoptosis in human colonic epithelial cell lines depending on the presence of alternative energy sources. Carcinogenesis 18, 1265-1270.

62. Knudsen KEB, Serena A, Canibe N, et al. (2003) New insights into butyrate metabolism. Proc Nutr Soc 62, 81-86.

63. Pool-Zobel BL, Selvaraju V, Sauer J, et al. (2005) Butyrate may enhance toxicological defence in primary, adenoma and tumor human colon cells by favourably modulating expression of glutathione $S$-transferases genes, an approach in nutrigenomics. Carcinogenesis 26, 1064-1076.

64. Nadkarni MA, Martin FE, Jacques NA, et al. (2002) Determination of bacterial load by real-time PCR using a broad-range (universal) probe and primers set. Microbiology 148, $257-266$

65. Institute of Grocery Distribution (2005) Review of Existing and Development of New GDAs: Decisions and Rationale Report of the IGD/PIC Industry Nutrition Strategy Group. Hertfordshire, UK. 